\title{
LAS COMPARECENCIAS DE LOS SENADORES DE DESIGNACIÓN AUTONÓMICA ANTE SUS RESPECTIVAS ASAMBLEAS, ¿PERO REALMENTE ES INCONSTITUCIONAL?
}

\author{
María GarRote de Marcos \\ Departamento de Derecho Constitucional \\ Facultad de Derecho \\ Universidad Complutense de Madrid \\ magarrot@ucm.es
}

\begin{abstract}
RESUMEN
En este artículo se examina un aspecto muy concreto referido a los senadores autonómicos, como son las comparecencias ante las asambleas legislativas que los designan. El tema ofrece interés porque es relativamente novedoso, pues dichas comparecencias se han empezado a regular de manera generalizada con ocasión de las reformas estatutarias e institucionales que se han introducido desde 2005, y existen ya algunos antecedentes de su puesta en práctica en algunas Comunidades Autónomas. Junto a ello, la STC 123/2017, de 2 de noviembre, que resuelve el recurso de inconstitucionalidad contra la Ley valenciana de designación de senadores, ha introducido algunos criterios que contribuyen a despejar un panorama que se mostraba incierto, aunque también plantea interrogantes de trascendencia constitucional de cara al futuro.

Palabras clave: senadores, asambleas autonómicas, comparecencias, Senado.
\end{abstract}

\section{ABSTRACT}

This article studies a very particular side to local senators, namely their appearances in front of the Houses which appoint them. Since this is relatively new it makes it quite an interesting subject, as such appearances have begun to be ruled on a general basis because of the statutory and institutional reforms introduced since 2005, and there is some background to its put into practice in certain autonomous communities. Together with that, Sentence 123/2017, 2 November, which rules the unconstitutionality appeal against Valencian Act on the Appointment of Senators, has introduced some criteria which helps clearing a cloudy and uncertain sky, although it also raises transcendental constitutional questions into the future.

Keywords: Senators, Autonomic assemblies, appearances, Senate.

\section{ZUSSAMENFASSUNG}

In diesem Artikel wird ein sehr konkreter Aspekt bezogen auf die Senatoren der Autonomen Regionen untersucht, wie das Erscheinen derselben vor den gesetzge- 
benden Versammlungen, die sie ernennen. Dieses Thema ist deswegen interessant, weil es relativ neu ist, da diese Auftritte in allgemeiner Weise aus Anlass der Reformen der Statuten der Autonomen Regionen und der Institutionen seit 2005 reguliert wurden. Bisher gibt es einige Beispiele der praktischen Umsetzung in einigen Autonomen Gemeinschaften. Hinzu kommt das Urteil des Verfassungsgerichts 123/2017, vom 2. November, welches die Klage auf Verfassungswidrigkeit gegen das valenzianische Gesetz der Benennung von Senatoren entscheidet. Dieser Urteilsspruch, der über die Klage auf Verfassungswidrigkeit des Valenzianischen Gesetzes zur Benennung von Senatoren urteilt, bat einige Kriterien eingebracht, die dazu beitragen, die unklare Lage einzelner Streitpunkte zu klären; gleichfalls wirft dieser Urteilsspruch jedoch auch Fragen zu den weitreichenden Folgen dieser Entscheidung in der Zukunft auf.

Schlüsselwörter: Senatoren, Versammlungen der Autonomen Regionen, öffentliche Auftritte, Senat.

SUMARIO: I. UN MARCO NORMATIVO CAÓTICO Y ASIMÉTRICO.-II. Y EN LA PRÁCTICA...-III. EL TRIBUNAL CONSTITUCIONAL DESPEJA ALGUNAS DUDAS, PERO AÑADE OTRAS.-IV. LLEGADOS A ESTE PUNTO, ¿QUÉ SE PUEDE ESPERAR?

Este artículo pretende ser un homenaje en memoria del profesor José Antonio Alonso de Antonio, compañero del Departamento de Derecho Constitucional de la Universidad Complutense de Madrid, que dedicó su vida a la docencia universitaria y a la investigación, con honestidad y mucho esfuerzo. Entre las diversas líneas de investigación que desarrolló el profesor Alonso de Antonio destaca, sin duda, la dedicada al estudio del Senado español. Precisamente, un trabajo suyo publicado en esta misma revista es el que me ha servido de fuente de inspiración para escribir estas líneas en su recuerdo. En él, el profesor Alonso de Antonio defendía una reforma de la composición del Senado que reforzara la designación de sus miembros por las Asambleas legislativas autonómicas, lo que impulsaría la integración de las Comunidades Autónomas en la estructura del Estado ${ }^{1}$.

\section{UN MARCO NORMATIVO CAÓTICO Y ASIMÉTRICO}

Han sido muy frecuentes y numerosas las críticas a la composición del Senado por su inadecuación con la naturaleza territorial que la Constitución atribuye a esta Cámara (art. 69 CE) y han abundado también las pro-

${ }^{1} \mathrm{~J}$. A. Alonso de Antonio, «Algunas propuestas para la reforma constitucional del Senado», Foro, núm. 2 (2005), pp. 359-407. 
puestas de reforma del modo de elección o reclutamiento de los senadores. Sin embargo, la figura de los senadores de designación autonómica ha sido poco estudiada como categoría individualizada, a pesar de que desde hace algunos años constituyen un elemento de creciente y significativo interés.

La Constitución apenas menciona en su art. 69.5 unas mínimas pautas para proceder a la designación de los senadores de designación autonómica: «Las Comunidades Autónomas designarán además un senador y otro más por cada millón de habitantes de su respectivo territorio. La designación corresponderá a la Asamblea legislativa o, en su defecto, al órgano colegiado superior de la Comunidad Autónoma, de acuerdo con lo que establezcan los Estatutos, que asegurarán, en todo caso, la adecuada representación proporcional».

El desarrollo de este artículo en la normativa estatal ha sido bastante conciso, ya que es esta una materia que corresponde regular a las Comunidades Autónomas ${ }^{2}$. En todo caso, esta parquedad no hace sino confirmar que el estatuto jurídico de estos senadores autonómicos es el mismo que el del resto de senadores electos.

Desde el principio el Tribunal Constitucional (STC 40/1981, de 18 de diciembre) ha hecho una interpretación amplia y flexible de la remisión del art. 69 a «lo que establezcan los Estatutos» para regular esta materia, y declaró constitucional la regulación por ley que se realizó en la Ley 4/1981, de 18 de marzo, del Parlamento Vasco, sobre designación de senadores representantes de Euskadi. Con ello quedó validada cualquiera de las fórmulas que se iban a utilizar, posteriormente, por las distintas Comunidades Autónomas.

Y esas fórmulas van a ser muy variadas desde la perspectiva formal y de diferente alcance en cuanto a su contenido material. Respecto a las fuentes formales, todas las Comunidades Autónomas recogen en sus Estatutos de Autonomía una referencia a la designación de los senadores autonómicos, si bien la mayoría solo lo contemplan como una función más del Par-

2 Así, las referencias que se recogen en el Reglamento del Senado se centran principalmente en el modo de perfeccionamiento de su condición de senadores y eventual cese (arts. 1, 12, 18 y 19), en su incorporación a los grupos parlamentarios (art. 28), incluidos los grupos territoriales (art. 32) y un especial tratamiento a los mismos en el funcionamiento de la Comisión General de las Comunidades Autónomas (art. 56 bis, 1 y 5). Por su parte, la Ley Orgánica de Régimen Electoral General solo se refiere a los senadores de designación autonómica para aclarar, en su art. 165.4, que el número concreto de senadores que corresponda a cada Comunidad Autónoma se determinará tomando como referencia el censo de población de Derecho vigente en el momento de celebrarse las últimas elecciones generales al Senado. 
lamento, limitándose a reproducir el art. 69.5 sin determinar procedimiento alguno ${ }^{3}$. En cambio, otros aluden específicamente a cuestiones como la necesidad de ostentar la condición de diputado de la Asamblea ${ }^{4}$, la vinculación del mandato de senador a la propia Asamblea o las eventuales comparecencias de los senadores ante la Cámara 5 .

En algunos casos se hace una remisión expresa a la ley para desarrollar el precepto estatutario. La regulación mediante ley de las condiciones para la designación de los senadores fue tempranamente aceptada por el Tribunal Constitucional en la mencionada STC 40/1981, siempre que la ley «se mueva dentro de los límites que resultan de una conexión con el carácter específico de su designación». De hecho, cada vez son más las Comunidades Autónomas que prefieren prever la regulación de esta materia en una ley en lugar de incluirla en el reglamentario parlamentario, y ello ha sido criticado por algunos, por entender que se trata de la ejecución de una competencia de la Asamblea y, por tanto, de una materia propiamente reglamentaria, con el riesgo añadido que puede comportar para la autonomía parlamentaria ${ }^{6}$. En todo caso, con remisión o sin ella, lo cierto es que once Comunidades Autónomas cuentan con una ley específica que regula la designación de los senadores, cuyo contenido en ocasiones repite el del reglamento parlamentario correspondiente. Junto a ello, también se han dictado normas que completan las disposiciones legales y reglamentarias en la materia, como las Resoluciones de la Presidencia en Andalucía, Aragón o Castilla-La Mancha ${ }^{7}$.

\footnotetext{
3 Asturias, Aragón, Castilla-La Mancha, Castilla y León, Murcia, Galicia, País Vasco y Navarra.

${ }^{4}$ Así lo prevén los Estatutos de Autonomía de Cantabria (art. 9), Extremadura (art. 16.2), Madrid (art. 16.3) y La Rioja (art. 19.1).

5 Es el caso de los Estatutos de Autonomía de Andalucía (art. 223), Baleares (art. 50), Cataluña (art. 179) y Canarias [art. 43.c)].

${ }^{6}$ Tanto Asensi Sabater como Sevilla Merino se mostraron a favor de la regulación por ley como medio preferible a la ordenación vía reglamento. Vid. J. Asensi SAbater y J. SEviLLA MeRINO, «La designación de senadores autonómicos en la perspectiva de la territorialización del Senado», en Jornadas de Parlamentos Autónomos, Valencia, Cortes Valencianas, 1986, pp. 107-119. Sin embargo, Saiz Arnaiz entiende que muchas de las disposiciones incluidas en estas leyes son más propias de reglamentos parlamentarios y cabe encuadrarlas como preceptos de contenido material de Derecho parlamentario. Vid. A. SAIz Arnaiz, «El Parlamento vasco: relieve constitucional, organización y funcionamiento», Revista de Estudios Políticos, núms. 46-47 (1985), pp. 159-160. En el mismo sentido se manifiesta P. GARCía Escudero, Los senadores designados por las Comunidades Autónomas, Madrid, Cortes Generales-Centro de Estudios Políticos y Constitucionales, 1995, p. 131.

7 Vid. Resolución de la Presidencia del Parlamento de Andalucía de 9 de abril de 2008, sobre la designación por el Parlamento de los senadores en representación de la Comunidad Autónoma de Andalucía (bttps://www.parlamentodeandalucia.es/opencms/export/portal-
} 
Esta diversidad de fuentes viene acompañada, además, de una asimetría sustantiva que hace gala de la autonomía que poseen las Comunidades Autónomas en esta materia. Varios son los aspectos relevantes que se deben contemplar con el fin de comparar el régimen jurídico que informa la designación de estos senadores en todas las Comunidades Autónomas y de los que me he ocupado en otro lugar ${ }^{8}$.

En cuanto al aspecto que nos interesa, las comparecencias de los senadores ante la Asamblea designante, estas se desenvuelven en el marco más amplio de las relaciones entre los senadores y sus Asambleas. La exigencia de ostentar la condición de diputado de la Asamblea autonómica para ser designado senador pone de manifiesto la especial y a veces intensa vinculación entre estos representantes y la Comunidad Autónoma de origen. Sin embargo, esta conexión directa y automática está dejando de ser la regla para convertirse en la excepción.

En efecto, se ha venido registrando una tendencia a desvincular el mandato de los senadores a la pertenencia a la Asamblea autonómica. Las recientes reformas llevadas a cabo, ya sea en los Estatutos de Autonomía, ya sea en las propias leyes de designación, han tendido a suprimir esta ligazón que, sin embargo, estaba presente con anterioridad en Andalucía, Aragón, Baleares, Castilla-La Mancha, Castilla y León, Cataluña, Extremadura y Canarias. Actualmente solo cuatro Comunidades Autónomas mantienen la necesidad de que el senador sea miembro de la Cámara, si bien en Extremadura se permite optar por mantener el escaño o dimitir ${ }^{9}$. De esta

web-parlamento/contenidos/pdf/PublicacionesOficiales/Resoluciones/RP-2008-01.pdf); Resolución de la Presidencia de las Cortes de Aragón de 20 de noviembre de 2013, sobre las comparecencias de los senadores en representación de la Comunidad Autónoma de Aragón ante la Comisión Institucional y de Desarrollo Estatutario (bttp://www.cortesaragon.es/ fileadmin/_DMZMedia/asesoria/resolucionesPresidencia/BOCA_191_ResolucionInterpretativa.pdf), y Norma interpretativa de la Presidencia de las Cortes de Castilla-La Mancha de 20 de noviembre de 2001, sobre el art. 100.1 del Reglamento de la Cámara (bttp://www.cortesclm.es/paginas/acuerdos/resolucion1.php).

${ }^{8}$ Estos elementos serían: a) número de senadores que corresponde a cada Comunidad Autónoma; $b$ ) requisitos de elegibilidad; c) procedimiento de presentación y selección de candidatos; $d$ ) votación, y e) relaciones entre los senadores y la Asamblea designante con posterioridad a la designación. Un repaso al panorama normativo sobre esta cuestión revela el distinto tratamiento que en cada ordenamiento autonómico se hace de estos senadores. Vid. M. GARROTE DE MARCOS, «Los senadores de designación autonómica y la teoría de los vasos comunicantes: panorámica actual y una reflexión para el futuro», Cuadernos de la Fundación Giménez Abad, num. 14 (2017), pp. 74-85.

9 Cantabria (arts. 9.8 EA y 2.1 de la Ley Electoral del Parlamento de Cantabria), Extremadura [art. 16.2.l) EA], Madrid (arts. 224 del Reglamento de la Asamblea y 10.8 EA) y La Rioja [arts. 19.1.l) EA y 2.1 de la Ley Electoral]. 
forma, la acumulación de mandatos solo se da en tres Comunidades Autónomas, dos de las cuales eligen a un único senador (Cantabria, La Rioja y Madrid). Algunos autores defienden esta vinculación por entender que potencia la representación autonómica (territorial) en el Senado ${ }^{10}$, pero la no acumulación de actas ha permitido formalizar las relaciones de los senadores con sus parlamentos regionales en un plano que quizá resulte más eficaz. Muchas Comunidades Autónomas prevén un régimen especial de relaciones que a priori son de difícil categorización jurídica.

Diez Comunidades Autónomas contemplan algún mecanismo de relación entre los senadores autonómicos y la Asamblea designante, con más o menos precisión en su regulación. Lógicamente, las cuatro Comunidades Autónomas que exigen ostentar la condición de diputado autonómico no prevén ningún tipo de enlace posterior, habida cuenta de la pertenencia del senador a la Cámara autonómica. Así, salvo Asturias, Galicia y Navarra - cuya normativa de designación ha permanecido sin apenas modificaciones desde los años ochenta-, el resto de Comunidades Autónomas han establecido reglas para garantizar la vinculación de sus senadores.

Para analizar adecuadamente las normas que regulan las relaciones entre senadores y Asambleas autonómicas se han clasificado estas en función del grado de rigidez que imponen a las mismas. Para ello se ha tenido en cuenta dos elementos: si los preceptos que prevén dichas relaciones se encuentran suficientemente desarrollados para poder ser aplicados y si los términos en los que se desenvuelven esas relaciones implican comparecencia personal ante algún órgano del Parlamento.

De esta manera tendríamos tres tipos de normativas: las más «leves», que por falta de desarrollo ulterior o por las previsiones que contemplan permiten ejercer un control o una vinculación frágil; las que se sitúan en término medio, y las «duras», que se encuentran más desarrolladas a nivel legal o reglamentario y que pormenorizadamente detallan las comparecencias de los senadores, que además son obligatorias.

Dentro de las reglas denominadas «leves» se incluyen las previstas en Castilla y León, Murcia y País Vasco. En Castilla y León solo se recoge una referencia a las eventuales relaciones de los senadores con la Cámara, cuyo

10 J. Asensi Sabater y J. Sevilla Merino, «La designación de senadores autonómicos...», op. cit., p. 117, y J. ElizAlde PéreZ, «Comentario al art. 69 de la Constitución», en Ó. Alzaga (dir.), Comentarios a las Leyes Políticas, t. VI, Madrid, Edersa, 1989, pp. 131 y ss. También recoge otras opiniones P. GARCía Escudero, Los senadores designados..., op. cit., pp. 157 y $239-242$. 
desarrollo se encomienda al Reglamento y aún no se ha producido (disposición adicional primera de la Ley de Designación) ${ }^{11}$. En Murcia, la Ley de Designación establece en su art. 8 que los senadores «podrán asistir a los Plenos de la Asamblea regional. No tendrán voto si no fueren diputados regionales, pero tendrán voz en los términos que establezca el Reglamento de la Asamblea» ${ }^{12}$. El Reglamento del Parlamento vasco (art. 233) señala que «los senadores tendrán reservado un escaño en el salón de sesiones del Parlamento, y les serán notificados cuantos asuntos pudieran ser de su interés en orden al mejor cumplimiento de sus funciones en el Senado. Además, el Pleno podrá solicitar a los senadores cuantos informes sobre sus actuaciones en el Senado puedan interesar a la Comunidad Autónoma del País Vasco, que deberán ser enviados a la Mesa del Parlamento para su posterior remisión a los grupos parlamentarios».

En estos tres casos, o bien se les permite la asistencia voluntaria a las sesiones de la Cámara, o bien se les puede requerir cierta información, pero que no implica la comparecencia personal.

En cuanto a las regulaciones que están en un término medio, podemos incluir las de Andalucía y Castilla-La Mancha. En Andalucía, el art. 223 de su Estatuto de Autonomía señala que los senadores elegidos o designados por Andalucía podrán comparecen ante el Parlamento en los términos que establezca su Reglamento para informar de su actividad en el Senado. En desarrollo de esta previsión estatutaria, el art. 8 de la Ley de Designación dispone que los senadores designados podrán comparecer ante el Parlamento para informar de su actividad en el Senado en los términos que determine el Reglamento del Parlamento de Andalucía. Es de destacar que en el Estatuto de Autonomía de Andalucía la posibilidad de comparecencia se extiende no solo a los senadores designados por el Parlamento andaluz, sino también a los senadores elegidos por el cuerpo electoral. De momento no se ha desarrollado reglamentariamente el régimen de estas comparecencias, si bien ya ha habido peticiones para comparecer de algún senador. En Castilla La-Mancha, el art. 3 de la Ley de Designación establece que: «Los senadores representantes de la Comunidad Autónoma facilitarán a las Cor-

11 «Las Cortes de Castilla y León adecuarán su Reglamento a lo dispuesto en esta Ley y determinarán las relaciones de los senadores con la Cámara».

${ }_{12} \mathrm{El}$ art. 98.7 del Reglamento de la Asamblea dispone que: «Los senadores representantes de la Comunidad Autónoma podrán intervenir a efectos meramente informativos cuando el Senado haya tramitado o tenga previsto tramitar alguna iniciativa sobre el asunto que está considerando la Asamblea, sin perjuicio de las facultades que, respecto a la ordenación de los debates, corresponden al presidente». 
tes regionales información, en la forma en que se determine por las normas de desarrollo de la presente Ley». Según el art. 100.1 del Reglamento de la Cámara manchega: «El senador o senadores representantes de la Junta de Comunidades de Castilla-La Mancha, en lo que suponga información de cuestiones tramitadas o en vías de trámite en el Senado y relativos a asuntos incluidos en el orden del día del Pleno, podrán hacer uso de la palabra siempre que lo soliciten, sin perjuicio de las facultades que para la ordenación de los debates corresponden al presidente de las Cortes». Este precepto ha sido objeto de una Norma interpretativa de la Presidencia de 20 de noviembre de 2001 que viene a delimitar con mayor precisión el alcance del mismo. En ella destaca la exigencia de una comunicación previa al presidente manifestando la intención de intervenir, en la que señalarán los datos que resulten útiles para comprobar que la cuestión sobre la que verse la información ha tenido entrada en el Senado. Asimismo, deberán indicar el asunto del orden del día del Pleno con el que se encuentre relacionado. Es decir, se requiere que las intervenciones de los senadores en el Pleno estén sobradamente justificadas por afectar a cuestiones de relevancia autonómica y tengan vinculación directa con la actividad del Senado.

Esta normativa integrada en el nivel medio se caracteriza por prever la posibilidad de que los senadores acudan a informar, o bien de su actividad en el Senado, o bien acerca de un asunto de interés y relevancia para las materias incluidas en el orden del día del Pleno. La limitación estricta del objeto de la información (Castilla-La Mancha), en un caso, y la falta de desarrollo reglamentario, en el otro (Andalucía), sitúan a estos regímenes en un punto medio.

El tercer tipo de regulación, que hemos denominado «dura», se encuentra recogida en Aragón, Islas Baleares, Canarias, Cataluña y Comunidad Valenciana.

La Ley de Designación de Aragón prevé un doble mecanismo de relación, a petición de los senadores y a solicitud de la Cámara. Así, el art. 12 señala: «1. Los senadores designados podrán comparecer en la Comisión Institucional una vez al año, de acuerdo con el presidente de las Cortes, para informar de las gestiones de interés para la Comunidad Autónoma de Aragón. 2. La mayoría de la Cámara, de acuerdo con su presidente, podrá solicitar su comparecencia ante la Comisión Institucional cuando la importancia y transcendencia de los temas en relación con la Comunidad Autónoma así lo aconseje».

El art. 243 del Reglamento de las Cortes reproduce básicamente lo establecido en la ley, aunque introduce una ligera modificación respecto a 
las solicitudes de comparecencia. Así, dispone en su apartado 2 que: «Dos grupos parlamentarios o una quinta parte de los diputados de la Cámara, de acuerdo con la Presidencia, podrán solicitar, asimismo, su comparecencia ante la Comisión Institucional y de Desarrollo Estatutario cuando la importancia y transcendencia de los temas en relación con la Comunidad Autónoma así lo aconsejen».

Esta previsión reglamentaria ha sido completada con una Resolución de la Presidencia de las Cortes de Aragón de 20 de noviembre de 2013, sobre las comparecencias de los senadores en representación de la Comunidad Autónoma de Aragón ante la Comisión Institucional y de Desarrollo Estatutario. En ella se detalla la ordenación de las comparecencias, con leves diferencias entre las que son a iniciativa de los senadores y las que provienen de la Cámara.

En Islas Baleares, el art. 50 de su Estatuto de Autonomía establece que los senadores «comparecerán ante la comisión parlamentaria pertinente a iniciativa propia o a requerimiento de un grupo parlamentario o de una quinta parte de los diputados para informar de su actividad en el Senado en los términos que establezca el Reglamento del Parlamento de las Illes Balears». El art. 189.8 del Reglamento del Parlamento reproduce el precepto estatutario.

En Canarias, el Reglamento parlamentario (art. 199) establece que: «El Pleno del Parlamento, a iniciativa de un grupo parlamentario, podrá solicitar a los senadores representantes de la Comunidad Autónoma su presencia para informar sobre aquellos asuntos relacionados con la actividad del Senado que resulten de interés para Canarias. Igual facultad corresponderá a las comisiones, previo acuerdo de la Mesa de la Cámara.

Junto a ello, también se prevén medidas para facilitar esas relaciones en los apartados 2 y 3: «2. La Mesa de la Cámara asignará a cada uno de los senadores representantes de la Comunidad Autónoma los medios que fueren necesarios para mantener su relación con el Parlamento de Canarias. 3. La Mesa adoptará las medidas oportunas a fin de que a los citados senadores les sean notificados cuantos asuntos sean tratados en el Parlamento de Canarias y que pudieran resultar de interés para el mejor desempeño de su mandato como senadores».

En Cataluña, el art. 179 de su Estatuto de Autonomía señala que: «Los senadores elegidos en Cataluña y los que representan a la Generalitat en el Senado pueden comparecer ante el Parlamento a petición propia para informar sobre su actividad en el Senado en los términos que establece el Reglamento del Parlamento». Al igual que en el Estatuto de Autonomía de Anda- 
lucía, se prevé la posibilidad de comparecencia de todos los senadores, tanto los electos como los designados, si bien el desarrollo posterior se ha centrado exclusivamente en los senadores de designación autonómica. La Ley de Designación (art. 9) contempla tanto la comparecencia a petición del senador como la solicitada por el Parlamento: «1. Los senadores que representan a la Generalidad en el Senado pueden comparecer ante el Parlamento cuando lo soliciten. 2. El Parlamento puede solicitar la comparecencia de los senadores que representan a la Generalidad en el Senado de acuerdo con lo establecido por el Reglamento del Parlamento».

Por su parte, el Reglamento completa las previsiones legales en el art. 172: «3. Los senadores que representan a la Generalidad en el Senado, a petición de la tercera parte de estos o por acuerdo de la comisión, deben comparecer en una sesión informativa para informar de sus actuaciones en el Senado respecto a cualquier tramitación relacionada con la Generalidad o con las Comunidades Autónomas. 4. Los senadores deben ser informados de los acuerdos y debates del Parlamento relacionados con la actividad y las competencias del Senado».

Por último, la Ley de Designación de la Comunidad Valencia, en la redacción dada por la Ley 10/2016, de 28 de octubre, en su art. 16 disponía que: «1. Los grupos parlamentarios podrán solicitar la comparecencia de los senadores y de las senadoras designados en representación de la Comunitat Valenciana para que informen sobre temas relacionados con la actividad parlamentaria, siguiendo el procedimiento que el Reglamento de Les Corts establezca para las comparecencias de los miembros del Consell. 2. En todo caso, al menos anualmente los senadores y las senadoras comparecerán ante la Comisión de Coordinación, Organización y Régimen de las Instituciones para rendir cuentas de su trabajo en el Senado. 3. La comparecencia del senador o senadora en virtud de lo establecido en este artículo serán de carácter obligatorio». El art. 17 prevé la asistencia de senadores al Pleno o a las Comisiones.

Como es sabido, esta norma ha sido declarada inconstitucional por la STC 123/2017 y, aunque más adelante abordaremos dicha decisión, baste decir que las anteriores leyes de designación de senadores valencianos ya incluían preceptos de similar contenido, si bien no tan contundentes en cuanto a la obligatoriedad de comparecer ${ }^{13}$.

13 El art. 16 de la Ley 9/2010, de 7 de julio, de designación de senadores o senadoras en representación de la Comunitat Valenciana, en su redacción originaria establecía: «1. A través de la Presidencia de Les Corts, y en la forma que determine el Reglamento de la Cámara, las comisiones podrán solicitar la comparecencia de las senadoras o senadores designados 
Dentro de este grupo de Comunidades Autónomas con normativa «dura» existen, no obstante, algunas diferencias. Casi todos atribuyen la iniciativa a un grupo parlamentario salvo Aragón, que exige la iniciativa de dos grupos. Algunos contemplan la comparecencia anual, como la Comunidad Valenciana o Aragón; en algún caso también se contempla que la Cámara autonómica facilite y proporcione la información necesaria al senador (señaladamente en Canarias). Solo la normativa de la Comunidad Valenciana decía expresamente que la comparecencia es obligatoria y, además, la equipara con las de los miembros del Consejo de Gobierno, lo que ha llevado al Tribunal Constitucional a declarar su inconstitucionalidad.

Como puede comprobarse, el panorama normativo de las comparecencias de los senadores es disperso y variado, y en todo caso obliga a preguntarse sobre tres cuestiones a las que intentaremos dar respuesta en las siguientes páginas. En primer lugar, la constitucionalidad de la normativa autonómica cuando va más allá de los supuestos analizados por la jurisprudencia constitucional (relativos a la duración del mandato o a ciertos requisitos complementarios de elegibilidad), normativa que añade una obligación singular al estatuto de ciertos senadores que se cumple en el ámbito de las instituciones autonómicas.

En segundo lugar, la incomparecencia del senador convocado no puede originar ninguna sanción jurídica, si acaso un reproche político. En este caso es claro que el senador de designación autonómica no está vinculado con la Asamblea designante por mandato alguno.

en representación de la Comunitat Valenciana para que informen sobre temas relacionados con su actividad parlamentaria de interés para la comisión solicitante.

2. Del mismo modo, los grupos parlamentarios podrán solicitar comparecencias ante las comisiones de la Cámara para informar sobre temas relacionados con su actividad parlamentaria de interés para la Comunitat Valenciana, siguiendo el procedimiento que el Reglamento de Les Corts establece para las comparecencias de los miembros del Consell.

3. Las senadoras o senadores designados en representación de la Comunitat Valenciana podrán, a través de la Presidencia de Les Corts, solicitar su comparecencia ante las comisiones de la Cámara para informar sobre temas relacionados con su actividad parlamentaria de interés para dichas comisiones, todo ello en la forma que determine el Reglamento de la Cámara.

4. En todos los supuestos, la comparecencia requerirá el previo acuerdo de la Mesa de Les Corts y de la Junta de Síndics».

Incluso en la Ley 3/1988, de 23 de mayo, de designación de senadores en representación de la Comunidad Valenciana, el art. 15 contemplaba también las comparecencias de los senadores: «Las comisiones, de acuerdo con el presidente de las Cortes, podrán solicitar la comparecencia de los senadores designados en representación de la Comunidad Valenciana para que informen sobre temas relacionados con su actividad parlamentaria». 
Por último, el trámite de comparecencia puede ser instrumentalizado por los grupos parlamentarios, ya sea por la mayoría o por las minorías, para obtener ventajas políticas, como ya ha acontecido en algunos Parlamentos autonómicos.

\section{Y EN LA PRÁCTICA...}

Hay que señalar que las comparecencias de los senadores ante las Asambleas designantes han sido ciertamente escasas. A veces esto se ha debido a la falta de desarrollo normativo de las previsiones legales, como en el caso de Andalucía. En junio de 2016, la senadora Maribel Mora (Podemos) solicitó comparecer ante el Parlamento andaluz y se le denegó por no estar contemplado en el Reglamento ${ }^{14}$. De hecho, en febrero de 2018 el Grupo Parlamentario Podemos presentó una proposición de reforma del Reglamento parlamentario para incluir en el mismo un artículo en el que se regulen las comparecencias de los senadores en el seno de la Comisión Consultiva de Nombramientos, Relaciones con otras Instituciones y Peticiones, de modo semejante a las comparecencias para la presentación del informe del Defensor o Defensora del Pueblo Andaluz en comisión, y que finalmente decayó por la finalización de la legislatura ${ }^{15}$.

En otros casos, las comparecencias se han solicitado aunque no se han celebrado finalmente. En Aragón, se solicitó la comparecencia de la senadora Luisa Fernanda Rudi, aunque para un asunto que nada tenía que ver

14 http://www.eldiario.es/andalucia/Podemos-Parlamento-Andalucia-comparecer-senadora _0_521798091.html.

15 Se propone la inclusión del art. 190 bis:

«1. El senador o senadora que represente a la Comunidad Autónoma de Andalucía por designación del Parlamento de Andalucía podrá comparecer, a petición propia, una vez en cada año natural ante la Comisión Consultiva de Nombramientos, Relaciones con otras Instituciones y Peticiones, para informar de su actividad en el Senado. La fecha fijada para esta comparecencia no podrá coincidir con la celebración de sesiones del Senado en las que deba participar el senador o senadora.

2. La comparecencia se desarrollará según las siguientes reglas:

1. ${ }^{\circ} \quad$ Exposición general del senador o senadora sobre su actividad en el Senado.

2. Intervención de los representantes de los distintos grupos parlamentarios, de menor a mayor, por diez minutos, para formular preguntas o solicitar aclaraciones.

3. Contestación del senador o senadora.

4. ${ }^{\circ}$ En su caso, nuevo turno de intervenciones de los representantes de los grupos parlamentarios, a cuyo efecto el presidente o presidenta de la comisión fijará el número y duración de las mismas». Vid. Boletín Oficial del Parlamento de Andalucía, núm. 655, X Legislatura, 12 de marzo de 2018. 
con su actividad en el Senado, sino con los sueldos que percibe ${ }^{16}$. La solicitud de comparecencia, presentada por Podemos, fue calificada por la Mesa de las Cortes y se le dio traslado a la Mesa de la Comisión Institucional, estando aún pendiente de celebración ${ }^{17}$. En Valencia, también se solicitó la comparecencia de la senadora Rita Barberá con un objetivo ajeno a su labor como senadora (dar explicaciones sobre la operación Taula) y ella manifestó su negativa a comparecer ${ }^{18}$.

No obstante, sí se han celebrado comparecencias en el Parlamento de Illes Balears, aunque el motivo de la comparecencia no fuera de interés autonómico. Así, Antich tuvo que comparecer para explicar la ayuda prestada a ERC para formar grupo parlamentario ${ }^{19}$.

También se solicitó la comparecencia de Bauzá para explicar su voto en contra de suprimir los aforamientos ${ }^{20}$. Y también la de ambos senadores para explicar su postura ante la aplicación del art. $155 \mathrm{CE}$ en Cataluña ${ }^{21}$.

Precisamente, la aplicación del art. 155 CE en Cataluña fue el asunto que centró la comparecencia de los ocho senadores designados por el Parlament de Cataluña ante al Comisión de Asuntos Institucionales el 24 de octubre de 2017. La comparecencia se produjo a instancias de JxSí, «para que informen sobre la aplicación y los efectos del art. 155 de la Constitución» para intervenir el autogobierno de Cataluña ${ }^{22}$.

Las comparecencias han tenido poco recorrido y han sido muy excepcionales, pero también ha habido algunas iniciativas legislativas para impulsar estas figuras, además de la ya mencionada en el Parlamento andaluz.

Antes del pronunciamiento del Tribunal Constitucional mediante STC 123/2017 se presentaron dos proposiciones de ley de Ciudadanos que pretendían introducir el cese o revocación de los senadores de desig-

\footnotetext{
16 https://www.abc.es/espana/aragon/abci-piden-rudi-explique-ante-cortes-aragon-doble -paga-cobra-cada-201804051805_noticia.btml.

17 https://www.cortesaragon.es/Nota-de-prensa.712+M59e63d0d871.0.html.

18 http://www.lavanguardia.com/local/valencia/20160229/4096237723/rita-barbera-evita-comparecer-corts-valencianes. $h$ tml.

19 http://www.elmundo.es/baleares/2016/02/10/56bb375922601d7a588b4598. btml.

20 http://www.lavanguardia.com/vida/20160929/41664351694/mes-pide-la-comparecencia-de-bauza-despues-de-que-votase-en-contra-de-suprimir-el-aforamiento-en-el-senado.btml.

${ }_{21}$ https://www.ultimahora.es/noticias/local/2017/10/21/301265/antich-bauza-deberancomparecer-parlament-explicar-voto-articulo-155-1.html.

22 bttps://www.eldiario.es/politica/senadores-catalanes-comparecen-Parlamento-catalan _0_700629973. html. Se puede ver el video de la comparecencia del senador Alegre en https://www.youtube.com/watch? $v=j Z 7 B 7 X e 0 m n 8$.
} 
nación autonómica en las Cortes de Castilla y León y en el Parlamento de La Rioja, junto con la regulación de las comparecencias de los senadores.

$\mathrm{La}$ «Proposición de Ley del procedimiento de designación, de las causas de cese y de las relaciones con el Parlamento del senador en representación de la Comunidad Autónoma de La Rioja» fue presentada por el Grupo Parlamentario Ciudadanos en febrero de 2017. La iniciativa no estuvo exenta de polémica. De hecho, la publicación de la proposición de ley viene precedida de un Acuerdo de Mesa del Parlamento en el que se manifiestan dudas sobre su posible inconstitucionalidad, ya que podría vulnerar el «bloque constitucional en el que se incluye nuestro Estatuto de Autonomía y que admitir la iniciativa equivaldría a pretender llevar a cabo una iniciativa de reforma del Estatuto en tanto que se modificaría el art. 19.1.l) sin los requisitos de legitimación precisos para ello establecidos en el art. 58.1 del mismo» ${ }^{23}$.

La finalidad de la iniciativa es, entre otras, establecer mecanismos de relación entre los senadores y la Asamblea autonómica que potencien su dimensión territorial para «llevar a cabo "las relaciones de inordinación" en nuestro Estado autonómico». La proposición de ley, además de prever un mecanismo de cese o revocación del senador, también incorpora «procedimientos de relación entre el senador designado y el Parlamento de La Rioja, a través de comparecencias regladas periódicas y otras extraordinarias, a instancia tanto de la Cámara como del propio senador, para que este rinda cuentas de su actividad ante la Cámara o para que los parlamentarios riojanos le transmitan sus posiciones sobre temas a debatir en el Senado» ${ }^{24}$. Entre estas comparecencias cabe destacar «la previsión de una comparecencia anual obligada para que el senador autonómico exponga

${ }^{23}$ Vid. Boletín Oficial del Parlamento de La Rioja, serie A, núm. 94, 8 de febrero de 2017, pp. 2220-2229.

24 «Art. 9. De las comparecencias.

1. El senador designado por el Parlamento de La Rioja en representación de la Comunidad Autónoma podrá comparecer ante el mismo a iniciativa propia para informar de su actividad en el Senado. Dichas comparecencias se producirán en los términos que determine el Reglamento del Parlamento de La Rioja.

2. El Parlamento de La Rioja podrá solicitar también la comparecencia del senador autonómico ante el Pleno del Parlamento de La Rioja siempre que la importancia y transcendencia de los temas en relación con la Comunidad Autónoma así lo aconsejen. Dichas comparecencias se producirán en los términos que determine el Reglamento del Parlamento de La Rioja.

3. En todo caso, una vez al año - y en la forma prevista en el Reglamento del Parlamento de La Rioja- el senador designado comparecerá ante el Pleno para informar de su actuación en el Senado en relación con los temas de interés para la Comunidad Autónoma de La Rioja. 
ante el Parlamento de La Rioja una memoria de las actividades realizadas en relación con la Comunidad Autónoma» ${ }^{25}$.

En la misma línea, en septiembre de 2017 se publicó la «Proposición de Ley por la que se regula el nombramiento y el control parlamentario de los senadores representantes de la Comunidad de Castilla y León», presentada por el Grupo Parlamentario Ciudadanos. El objetivo de esta nueva regulación sería, de un lado, «potenciar el sistema de control parlamentario del proceso de designación de estos senadores, así como establecer cauces de control parlamentario por parte de las Cortes de Castilla y León de la actividad de los mismos». Para ello se promueve un «sistema de rendición de cuentas a través principalmente de dos cauces: el de la audiencia previa de los candidatos a desempeñar dichas funciones y el de las comparecencias anuales obligatorias - y sin límite a petición propia o de parte de los procuradores- de los senadores ante las Cortes de Castilla y León incluyendo informe previo para explicar dicho desempeño» ${ }^{26}$.

Con independencia de la ya rotunda inconstitucionalidad del cese o revocación de los senadores autonómicos por parte de la Asamblea designante - una vez que el Tribunal Constitucional se ha pronunciado sobre ello_-, llama la atención que en ambas iniciativas se incorpora la figura de la comparecencia obligatoria ante la Asamblea, incluso en el caso de La Rioja, donde para ser senador es imprescindible ostentar la condición de parlamentario autonómico.

4. Las comparecencias del senador autonómico en virtud de lo establecido en los apartados 2 y 3 de este artículo serán de carácter obligatorio».

${ }^{25}$ «Art. 10. Del informe anual. Cada año, una vez finalizado el segundo periodo de sesiones del Senado, el senador designado presentará ante el Pleno del Parlamento de La Rioja un informe en el que dará cuenta de su actuación en relación con los temas de interés para la Comunidad Autónoma de La Rioja. La presentación de dicho informe será seguida de un debate con los portavoces de los distintos grupos parlamentarios en los términos previstos en el Reglamento del Parlamento de La Rioja».

26 «Art. 9 .

1. Los senadores deberán comparecer al menos una vez al año ante el Pleno de las Cortes de Castilla y León, previa presentación a la Mesa de las Cortes y a los grupos parlamentarios de un informe acreditativo de las actividades llevadas a cabo en virtud de su designación.

2. Podrán existir comparecencias extraordinarias de los senadores autonómicos a petición propia, de al menos un tercio de los miembros de las Cortes de Castilla y León o de dos grupos parlamentarios». Vid. Boletín Oficial de las Cortes de Castilla y León, núm. 317, IX Legislatura, 26 de septiembre de 2017, pp. 40308-40315. 


\section{EL TRIBUNAL CONSTITUCIONAL DESPEJA ALGUNAS DUDAS, PERO AÑADE OTRAS}

Tras la reforma de la Ley 9/2010, de 7 de julio, de Designación de Senadores en representación de la Comunitat Valenciana, operada por la Ley 10/2016, de 28 de octubre, se introducen dos importantes modificaciones que afectan directamente a la naturaleza del mandato parlamentario de dichos senadores y al eventual control de su actuación. Dicha reforma añadía un nuevo artículo (14 bis) titulado «De la revocación», en cuya virtud el «nombramiento» de los senadores designados por Les Corts valencianas según lo dispuesto en los arts. 69.5 CE y 22.j) EAV podría ser revocado por la propia Asamblea autonómica conforme al procedimiento que allî se establece; procedimiento iniciado a partir de una propuesta parlamentaria motivada en la «pérdida de confianza» por el «incumplimiento de las obligaciones del senador o senadora establecidas en la actual ley, así como actuaciones que comporten el desprestigio de las instituciones».

Junto a ello, la reforma incorporaba dos apartados al art. 16 (cuyo apartado 1 preveía la posibilidad de solicitar la comparecencia de los senadores). El apartado 2 establecía que: «En todo caso, al menos anualmente los senadores y las senadoras comparecerán ante la Comisión de Coordinación, Organización y Régimen de las Instituciones para rendir cuentas de su trabajo en el Senado», mientras que el apartado 3 afirmaba la obligatoriedad de dichas comparecencias sin reservas: «La comparecencia del senador o senadora en virtud de lo establecido en este artículo serán de carácter obligatorio».

La Ley 10/2016 fue impugnada ante el Tribunal Constitucional mediante la interposición de un recurso de inconstitucionalidad promovido por más de cincuenta senadores del Grupo Parlamentario Popular en febrero de 2017. La STC 123/2017, de 2 de noviembre, resuelve dicho recurso estimando la inconstitucionalidad de los preceptos impugnados.

Dejando a un lado la cuestión de la revocación del mandato, de enorme relevancia, pero que queda fuera de nuestro análisis, la sentencia aporta algunas pautas sobre el régimen jurídico de las comparecencias que resultan enormemente reveladoras ${ }^{27}$.

27 Sobre esta cuestión vid. C. FERNÁNDEZ EsQuer, «La posible inconstitucionalidad de la Ley 10/2016, de modificación de la Ley 9/2010, de designación de senadores o senadoras en representación de la Comunitat Valenciana», Comunicación presentada al XV Congreso de la Asociación de Constitucionalistas de España, celebrado en León los días 30 y 31 de 
El Tribunal Constitucional aborda el examen de constitucionalidad de las comparecencias sobre dos ejes: el primer eje se centra en el apartado 3 del art. 16, que declara obligatorias las comparecencias de los senadores ante el Parlamento valenciano (FJ 4. ${ }^{\circ}$ ). Comienza afirmando este Tribunal que la previsión de comparecencias «son, de principio, inocuas desde el punto de vista de la constitucionalidad, en tanto se limiten a contemplar meras iniciativas parlamentarias con efectos jurídicos acotados a la vida interna de las Cámaras y sin alcance vinculante alguno, por tanto, para el senador cuya presencia se interesa. Normas de este carácter y con ese limitado alcance existen, por lo demás, en la legislación o en los reglamentos parlamentarios de algunas otras Comunidades Autónomas, contemplándose en ocasiones en tales normas, adicionalmente, la comparecencia parlamentaria de los senadores designados también a petición propia». Sin embargo, «tales normas autonómicas no pueden, al hilo de semejantes previsiones, imponer deber de tipo alguno sobre aquellos senadores, miembros de un órgano constitucional del Estado por entero sustraído a las competencias de las Comunidades Autónomas».

En este sentido, se entiende que el art. 16.3 se ha dictado «sin sustento en competencia autonómica alguna y es ya, solo por ello, contrario al propio Estatuto de Autonomía y, en consecuencia, inconstitucional». Apoya dicha argumentación en dos razones: en primer lugar, las normas autonómicas no pueden disciplinar, sin más, el régimen de los senadores designados, los cuales, conforme a los arts. 69.5 CE y 22.j) EAV, quedan parcialmente sometidos al ordenamiento jurídico estatutario solo en lo que hace a «las condiciones y modalidades de su designación» [STC 40/1981, FJ 1.e)]. Por tanto, la normativa autonómica se debe limitar a regular el modo de designación y solo eso.

En segundo lugar, «no cabe en modo alguno parangonar, en orden a lo que esté a su respectivo alcance, una ley autonómica con un Estatuto de Autonomía, aprobado este último mediante una ley orgánica del Estado y en el que puede sin duda establecerse, como condición de elegibilidad y de mantenimiento en el cargo, que los senadores que van a ser designados ostenten y conserven durante su mandato la condición de miembros de la respectiva Asamblea autonómica». En este sentido, la objeción de

marzo de 2017, disponible en https://congresoace.files.wordpress.com/2017/03/mesa1comunicacioncfernandezesquer.pdf.

V. Navarro Merchante, «La revocación de senadores de designación autonómica (la Ley valenciana 10/2016 y la STC 123/2017)», Revista de Derecho Político, núm. 101, (2018), pp. 123-157. 
inconstitucionalidad sería más formal que material, pues, como reconoce el propio Tribunal, «no ha de pronunciarse ahora sobre si la norma que así hemos de declarar inconstitucional no lo hubiera sido de haber estado contenida en el Estatuto de Autonomía para la Comunidad Valenciana».

El segundo eje tiene como objeto el apartado 2 del art. 16, que determina la comparecencia anual de los senadores «para rendir cuentas de su trabajo en el Senado». El Tribunal entiende que es inconstitucional tanto en atención a consideraciones competenciales como sustantivas. Respecto a las primeras, baste remitirse a lo dicho anteriormente sobre la ausencia de base estatutaria alguna. En cuanto a las consideraciones sustantivas, al Tribunal le parece evidente la contradicción material con la Constitución (art. 67.2), pues «sitúa a estos senadores en una inequívoca situación de subordinación a la Asamblea, o de dependencia política de la misma, al modo de la relación fiduciaria que vincula a un gobierno parlamentario [...]. Se trata, en definitiva, de un precepto que solo podría haber sido establecido por la Constitución misma, no por ninguna otra fuente, estatal o autonómica, a ella subordinada». Concluye que no se puede, sin vulnerar la Constitución, someter «la actuación del senador al escrutinio y fiscalización de la asamblea y transformando así el libre mandato político que ostenta aquel en lo que constituye, sin más, su contrario, es decir, en una figura próxima, si no idéntica, al mandato de Derecho privado».

La decisión del Tribunal Constitucional fue, en cierto modo, la esperada. Deja claro que las relaciones entre los senadores y las Asambleas designantes deben ceñirse, en principio, solo a las condiciones de elegibilidad y al modo de designación, que es básicamente lo que se deduce del art. 69.5 CE. No obstante, reconoce como un hecho indiscutible que la posibilidad de comparecer ante las Asambleas legislativas constituye «una específica vía interparlamentaria para la verificación, también en este concreto ámbito, de un principio general de colaboración que está implícito en la propia esencia de la forma de organización territorial del Estado y es consustancial, por tanto, al modelo del Estado de las autonomías».

Por tanto, la previsión (y celebración) de comparecencias no son «inconciliables con la Constitución, ello sin perjuicio de que su sede más apropiada, en tanto que configuran un mero procedimiento parlamentario y agotan por ello sus efectos en la dimensión interna de las asambleas, sea el reglamento de la Cámara respectiva». Aquí el Tribunal parece inclinarse, con buena lógica, por una regulación reglamentaria, pues la materia es de Derecho parlamentario, aunque su previsión en la Ley de Designación no sea inconstitucional, siempre que no se imponga como obligatoria. 
Cuando la comparecencia tiene carácter obligatorio parece que se requiere su inclusión en el Estatuto de Autonomía, si bien la argumentación del Tribunal Constitucional no deja claro si la eventual inconstitucionalidad de la obligatoriedad reside solo en su ubicación normativa o también en su abierta contradicción material con la Constitución. En este sentido, el Tribunal despeja algunas dudas, pero abre otras, pues tanto Baleares como Cataluña prevén comparecencias obligatorias en diferentes fuentes normativas ${ }^{28}$.

Lo que parece estar en abierta contradicción con el art. 67.2 CE es la posibilidad de exigir una rendición de cuentas a los senadores, con independencia de que se regule en el Estatuto de Autonomía, en el reglamento parlamentario o en la ley autonómica.

\section{LLEGADOS A ESTE PUNTO, ¿QUÉ SE PUEDE ESPERAR?}

Cada vez tiene más sentido sostener que los senadores de designación autonómica poseen una representatividad propia y diferente, aunque, a todos los efectos jurídicos, su estatuto sea el mismo que el de los electos. Algunos estudios han puesto de manifiesto que sus características personales, profesionales y políticas, su modo de designación, sus antecedentes y las responsabilidades que asumen en la organización y dirección del Senado dotan a este grupo de senadores de unas características propias y permiten considerarlo singularmente ${ }^{29}$. Además, hay que tener en cuenta que en muchos casos estos senadores son los únicos representantes de ciertos partidos en el Senado, que de otro modo tiene muy difícil conseguir un escaño en la Cámara, habida cuenta del sistema mayoritario de elección ${ }^{30}$. En definitiva, un enfoque finalista de las normas que regulan el Senado en

${ }^{28}$ En Baleares se recoge en el art. 50 EA, mientras que en Cataluña se regula en el art. 172.3 del Reglamento del Parlamento.

${ }_{29}$ F. J. Visiedo MAzón, «La designación de senadores en la Comunidad Valenciana. Artículo 11.j) del Estatuto de Autonomía: las limitadas posibilidades de mejora a través de la reforma de la Ley de Designación y del Reglamento de las Cortes Valencianas», Corts, núm. 12 (2002), pp. 269-304; J. M. Morales Arroyo, Informe sobre la reforma del Senado, Sevilla, Centro de Estudios Andaluces, 2006, pp. 44-54, disponible en bttps://www.centrodeestudiosandaluces.es/datos/actividades/Informe_Senado.pdf, y M. GARROTE DE MARCos, «Los senadores de designación...», op. cit., pp. 86 y ss.

${ }^{30}$ En la XII Legislatura, Ciudadanos obtiene tres senadores por esta vía; Compromís, Coalición Canaria y Bildu tienen uno cada uno. Algunos partidos obtienen representación en el Senado en ciertas Comunidades Autónomas solo mediante la designación, como es el caso del PP y PSOE en Cataluña, el PSOE en el País Vasco, y Podemos en Andalucía y Castilla-La Mancha. 
la Constitución permite afirmar que con estos senadores se buscaba trasladar las sensibilidades autonómicas a una Cámara de ámbito estatal, dando a estos representantes un perfil diferente. Y el Tribunal Constitucional ve en ello un aspecto de la autonomía ${ }^{31}$.

Se está registrando una clara tendencia a incorporar diferentes instrumentos de relación entre los senadores y las Asambleas una vez que se ha prescindido de la vinculación de mandatos. Algunos consisten en la obligación de celebrar comparecencias previas a los nombramientos, otros se refieren a la posibilidad de proporcionar y recibir información de estos senadores en asuntos de relevancia autonómica. Ninguno de estos mecanismos ha suscitado problemas; sin embargo, las comparecencias de los senadores después de su designación plantean ciertas dudas, de fondo y de forma, y que básicamente se pueden resumir en tres cuestiones:

Primero, la constitucionalidad de la normativa autonómica cuando incorpora no solo una posibilidad, sino una obligación singular al estatuto de estos senadores. Tras la STC 123/2017 es evidente que la posibilidad de comparecencia, mientras sea de carácter disponible, no es contraria a la Constitución, si bien su regulación formal debería ubicarse en el Reglamento parlamentario, al ser una materia de este carácter. Sin embargo, la mayoría de las Comunidades Autónomas prevén estas comparecencias en sus leyes de designación, probablemente por su menor rigidez normativa ${ }^{32}$.

Si las comparecencias se contemplan como una obligación entonces parece que es necesario preverlo en el Estatuto de Autonomía, pues de otro modo existe un vicio de inconstitucionalidad por vulnerar los respectivos ámbitos competenciales del Estado y las Comunidades Autónomas. En cualquier caso, el Tribunal Constitucional no ha sido suficientemente claro en este punto y ello pone en duda la ortodoxia de la normativa catalana, por ejemplo, cuyo Estatuto de Autonomía prevé la posibilidad de comparecencia, mientras que el Reglamento parlamentario impone la misma.

En segundo lugar, previstas las comparecencias en la normativa autonómica, ¿existe alguna sanción para el senador que se niega a comparecer? Claramente no una sanción jurídica, aunque quizá sí pueda desencadenar efectos políticos ${ }^{33}$. En este caso es claro que el senador de designa-

${ }^{31}$ Las Comunidades Autónomas «pueden participar en la determinación de tal política en virtud de la representación específica que las distintas comunidades autónomas tienen en el Senado» (STC 35/1982, de 14 de junio, FJ 2. ${ }^{\circ}$ ).

32 Quizá también por eso se haya acudido en algunos casos a las resoluciones de la Presidencia de la Cámara, cuya idoneidad también puede suscitar dudas.

33 Así, el Estatuto de Autonomía resulta norma suficiente para establecer el deber de 
ción autonómica no está vinculado con la Asamblea designante por mandato alguno, como ha afirmado con absoluta rotundidad el Tribunal en la STC 123/2017. Ello no es óbice para que la negativa a comparecer pueda interpretarse como un gesto de menosprecio hacia la Asamblea.

Por último, a nadie se le escapa que las comparecencias pueden ser utilizadas como «armas arrojadizas» en la dialéctica política de los grupos parlamentarios de la mayoría y la minoría ${ }^{34}$. Tanto si se abusa de las comparecencias para desgastar al partido en el Gobierno, convocando reiteradamente a los senadores designados por la mayoría, como si se fuerza desmesuradamente la presencia de los senadores designados por la oposición y se bloquea sistemáticamente la de los nombrados por la mayoría. Pero ello, a nuestro entender, entra dentro del juego político y de la dinámica parlamentaria. $\mathrm{Y}$ así es como creemos que debe entenderse este mecanismo, como un instrumento más a disposición de la Asamblea y sus grupos, sin más pretensiones que la de ser un medio útil para el diálogo institucional y sin más trascendencia que la meramente política.

Así las cosas, aunque hay quien niega no ya el carácter territorial del Senado, sino el de la propia representación ${ }^{35}$, parece que en un Estado descentralizado como el nuestro sería un error desaprovechar la oportunidad de conexión institucional que brinda la figura del senador designado. Muchos lo han entendido así. Para Aja y Arbós, estos senadores son la «voz permanente de las CCAA en los órganos centrales del Estado» ${ }^{36}$, y esta vinculación facilita, en opinión de Sáiz Arnaiz, «la continua comunicación entre los poderes legislativos central y autonómico» ${ }^{37}$. La eviden-

comparecencia y el reglamento parlamentario puede definir los trámites de la comparecencia, pero el estatuto de los senadores, como cargo público representativo, solo puede ser configurado por la norma reglamentaria del Senado. Vid. J. M. Morales Arroyo, «Artículo 223. Senadores por Andalucía», en P. Cruz Villalón y M. Medina Guerrero (dirs.), Comentarios al Estatuto de Autonomía para Andalucía, t. I, Sevilla, Parlamento de Andalucía, 2012, p. 3087.

${ }^{34}$ Para Visiedo Mazón esta es una muestra de la función electiva de las Cámaras que supone un incremento de la cuota de control del Parlamento, con publicidad y con debate ya sea este expreso o no. Vid. F. J. VISIEDO MAZÓN, «La designación de senadores...», op. cit., p. 289.

35 Entre otros, C. López GARRIDO, «Pero... ¿puede ser el Senado una Cámara de representación territorial?», Revista Española de Derecho Constitucional, núm. 107 (2016), pp. 75-116, y F. CAAmaño Domínguez, «Edmund Burke ha vuelto a morir (Parlamento y descentralización política)», Teoría y Realidad Constitucional, núm. 41 (2018), pp. 59-82.

36 E. Aja y X. Arbós, «El Senado: Cámara posible de las autonomías», Revista de Estudios Políticos, núm. 17 (1980), p. 64.

37 A. SAIZ ARnaiz, «El Parlamento vasco. Relieve constitucional, organización y funcionamiento», Revista de Estudios Políticos, núm. 46-47 (1985), p. 158. 
te debilidad del Senado como cámara de representación territorial aconseja, para Tudela Aranda, que se aprovechen al máximo estos mecanismos de modo que sirvan a una mejor integración del Estado autonómico ${ }^{38}$. Visiedo Mazón apostaba por incrementar los mecanismos de relación, respetando la prohibición de mandato imperativo, y convertir en periódicas las comparecencias, «para atender las sugerencias que puedan formularles los diputados o simplemente para exponer lo que ha sido su labor, en la Cámara Alta, desde su designación» ${ }^{39}$. Esta propuesta permitiría sortear los recelos que pueden suscitar las comparecencias a petición de los grupos o por decisión de la Mesa, y creemos que convirtiendo este instrumento en una práctica rutinaria se podría reforzar el vínculo entre los senadores y la Asamblea, sin someterlo a decisiones políticas de carácter coyuntural, como ha sucedido con frecuencia hasta ahora.

No sabemos qué deparará el futuro, pero todo apunta a que este canal de comunicación se verá reforzado. Prueba de ello son las iniciativas legislativas que se han presentado, que, aunque con contenidos diversos, apuestan por la celebración de comparecencias y revelan una inquietud política cada vez más relevante ante la repercusión que ha tenido la transformación del sistema de partidos en las Asambleas autonómicas y, a través de ellas, en el propio Senado ${ }^{40}$.

38 J. Tudela Aranda, «Naturaleza y funciones de las Cortes de Aragón», Derecho de las Instituciones Públicas Aragonesas, Zaragoza, El Justicia de Aragón, 2001, pp. 102-103.

39 F. J. VIsIEdo MAZÓN, «La designación de senadores...», op. cit., p. 290.

40 Como apunte de última hora, el partido Vox ha conseguido designar a un senador de su formación en el recientemente constituido Parlamento de Andalucía. Vid. http://www.parlamentodeandalucia.es/webdinamica/portal-web-parlamento/ actualidad/comunicadosdeprensa.do?id=136294. 